\title{
The Use of Role Playing in Engineering Curricula: a Case Study in Human-Automation Systems
}

\author{
P. Ponsa \\ Automatic Control Department. \\ Technical University of Catalonia, \\ EPSEVG, UPC, Av. Victor Balaguer \\ s/n 08800, Vilanova i la Geltrú, \\ Spain \\ Pedro.ponsa@upc.edu
}

\author{
R. Vilanova \\ Dept. Telecomunicació i Enginyeria \\ de Sistemes \\ Universitat Autònoma de Barcelona \\ ETSE, Campus UAB, 08913, \\ Bellaterra, Spain \\ Ramon.vilanova@uab.cat
}

\author{
B. Amante \\ Dept. Projectes de Enginyeria \\ Technical University of Catalonia \\ ETSEIAT, UPC, c/Colom 11, 08222, \\ Terrassa, Spain \\ Beatriz.amante@upc.edu
}

\begin{abstract}
This communication presents a collaborative experience between four Spanish centers: the School of Engineering (ETSE) and the Sports Services Area (SAF) both from the Universitat Autònoma de Barcelona (UAB) jointly with two centers of the Technical University of Catalonia, the high school from Vilanova i la Geltru (EPSEVG) and the high school in Terrassa (ETSEIAT). The idea behind this collaboration is to explore the possibility of role engineering education and project development for engineering students. The basic principle of such projects is the identification of the corresponding roles associated with the different parts that can be found on current social/industrial activity.
\end{abstract}

Keywords-component; role-playing; project-based learning, effectiveness and satisfaction metrics

\section{INTRODUCTION}

The Role Playing is used in our work as a methodological tool to provide students an appreciation of the range of issues and problems associated with engineering requirements in a real framework [1]. The Role Playing strategy is a successful tool used, for example, in software engineering education. The Role Playing is used in our work as a methodological tool to provide students an appreciation of the range of issues and problems associated with engineering requirements in real settings [1], [2]. An integrated framework is developed in order to improve the relationship between the Role Playing strategies inside the educational theory of Technological Pedagogical Content Knowledgement [3]. One interesting approach is to establish a relationship between the use of the role playing approach and the realization of an engineering project.

Among all possible different engineering curricula that can be found around (see [4] for a few examples) it is recognized the value of hands-on experiments and realization of project courses. Effectively, the realization of a project, usually during the last year of the degree, allows the student to face with a somewhat large problem where he/she has to be able to tackle the analysis and design stages as well as considerations on technology for implementation. The motivation for this communication is to show how opportunities for real world control and automation applications can be found on the immediate student environment.

This paper presents the application of the Role Playing methodology in engineering classroom from the point of view of an industrial automation case study. Finally we will explain the feedback of the SAF staff and the effectiveness of this method with the aid of well defined usability metrics.

\section{INDUSTRIAL-ACADEMIC COOPERATION}

The "UAB" is a campus based university with more than 40.000 inhabitants (students, academics, staff, etc). In fact, this makes the University campus to behave like a city with some sort of facilities offered for their inhabitants. Among them, the Sports Service Area (SAF) is one of the largest and with more complex installations [5].

Due to the evidence for the need of introducing new control elements and to integrate the different subsystems to help the SAF management staff the collaboration between both entities (SAF and the Automation and Systems Engineering Group) has emerged (see Fig. 1). The interesting point is that we decided to develop the collaboration under the form of engineering projects for undergraduate students.

Each academic year, before summer, it is time to prepare the engineering projects to be developed during the next year. This way the students can look at the different offers and present their applications.

From the SAF management a list of automation and control problems is first elaborated. From this list (jointly elaborated with the academics), a subset of problems that are realizable as an undergraduate project is identified and offered to the students. From this point students should apply for one project by presenting their $\mathrm{CV}$ and explaining the motivation and reasons for doing such project. Once the selection is done, a first joint meeting between the customer (SAF management), Project Direction (Academic staff) and Project developers (the students) is done. 


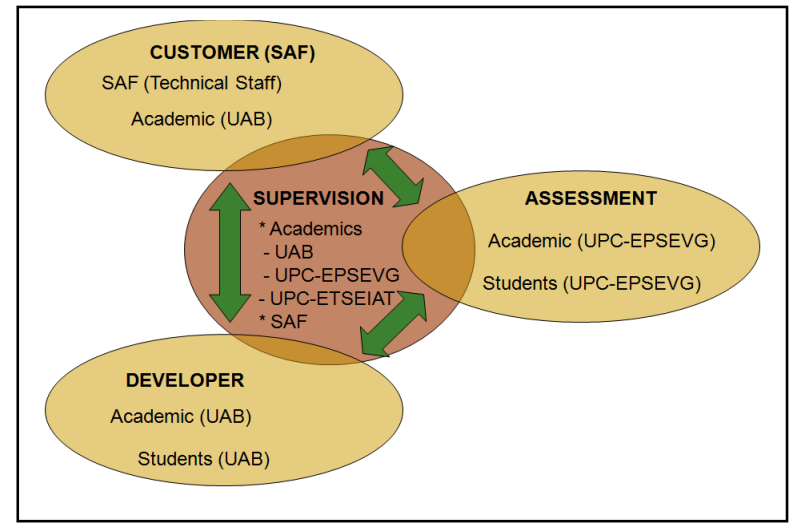

Figure 1. Identified roles and intercation between partners

From this point each student has a calendar of meetings (usually every 15 days) between him, the SAF management and the academics associated with the project. If any of the projects needs to collaborate with the work being developed on another project, there is a joint meeting where each one exposes their needs in order to find a joint solution.

Due to the evidence for the need of introducing new engineering system elements and to integrate the different subsystems to help the SAF management staff the collaboration between external entities has emerged. In this context, the SAF entity plays the customer role (maintenance functions), the ETSE member plays the software development role (monitoring and control interface), the ETSEIAT member provide us with the project-based learning approach and the EPSEVG member give us the human-centred automation approach [6]. The control engineering students from EPSEVG center have assigned the following roles: software developers (in order to build new supervisory control interfaces), designers (in order to apply ergonomics recommendations to display design), project management and usability engineers (in order to prepare usability testing and measure efficiency, effectiveness and satisfaction of the SAF human supervisors).

\section{ENGINEERING STUdENTS IN THE ROLE OF HUMAN OPERATORS}

From the framework described in the preceding section as the starting point, the experience is now driven one step forward and a third element is introduced: the external assessment role. The motivation for the introduction of this factor and force it to be developed on a different university (therefore geographically distributed and from a different educational framework/environment) is to create an atmosphere as similar as possible to the one the students will face within their professional life. The total interacting group is therefore constituted of three teams. Each team has a leading academic and a group of students. In addition, each team has associated specific roles corresponding to the professional activity they have to play. The development of such roles is mainly based on scientific and technological skills. These skills will be supervised and evaluated by the corresponding leading academic. In addition, other cooperation and interpersonal skills are to be considered.
These skills (Table I) will be considered by a team that integrates the leading academic members of each team. The relevance of effective teamwork is very important in the successful operation of control room environments. According to this idea it's necessary to define a set of competencies [7].

TABLE I. COMPETENCIES REQUIRED FOR A CONTROL ROOM OPERATOR

\begin{tabular}{|l|}
\hline \multicolumn{1}{|c|}{ Potencial competencies } \\
\hline Have a good knowledge of drills and procedures \\
\hline Be able to operate control equipment accurately \\
\hline $\begin{array}{l}\text { Understand the theory andd application of the control } \\
\text { process }\end{array}$ \\
\hline Understand the safety aspects of control room operations \\
\hline Be able to make appropiate decisions \\
\hline Be able to assess a situation accurately \\
\hline Be able to deal with stress and time pressure \\
\hline $\begin{array}{l}\text { Ensure that team goals, roles and responsibilities are } \\
\text { understood }\end{array}$ \\
\hline Be able to anticipate colleagues' requirements \\
\hline $\begin{array}{l}\text { Be able to pass the correct information to colleagues at the } \\
\text { right time }\end{array}$ \\
\hline $\begin{array}{l}\text { Be able to notice overloaded colleagues and support them } \\
\text { appropriately }\end{array}$ \\
\hline Be able to think ahead and develop cintingencies \\
\hline Ensure that colleagues maintains a shared understanding \\
\hline
\end{tabular}

The research in team training has been focused on training the members of a team together as a composite unit. The control engineering students from the EPSEVG center have the following roles: software developers (in order to build new supervisory control interfaces), designers (in order to apply ergonomics recommendations to display design), and usability engineers (in order to prepare usability testing and measure efficiency, effectiveness and satisfaction of the SAF human supervisors). At the EPSEVG center, a production systems laboratory that incorporates a Flexible Manufacturing System (FMS) is available. The control engineering students work in 2-people groups. Each group has a role inside the academic FMS and receives training about display design and systems maintenance.

This paper presents the application of the Role Playing method in engineering class from the point of view of an industrial automation case study in the following terms:

- One engineering student (Msc Automatic Control and Robotics from the Technical University of Catalonia) in the role of control room designer have been developing a new SAF layout in order to identify all the tasks (supervisory control, maintenance, display design and usability testing). This student made a meeting and a questionnaire with the SAF staff in order to obtain information about the physical and mental workload (see subsection A below).

- Some engineering students (MsC Engineeering in Automation and Industrial Electronics from technical school EPSEVG and ETSEIAT) have been using the display design ergonomics guideline (GEDIS guideline [8]) in order to improve the interface 
quality. In these moments, one student is programming these changes in order to improve the quality of the SAF monitoring interface (see subsection B).

Finally we will present the feedback received from the SAF staff and the effectiveness of this method with the aid of well defined usability metrics as well as future steps [9].

\section{A. Supervisory control task in the SAF Project}

After a meeting among the SAF manager staff and the external assessment, it is necessary to show the SAF manager staff a set of important recommendations along the lines of the following:

- Train maintenance operators in supervisory control tasks (monitoring and alarm systems)

- Improvement of the feedback between the manager, the maintenance operators and the software developers

- Re-design the control center layout in order to define a control room (see Fig. 2). It is necessary just to establish the functionality for each room and translate the meetings inside a meeting room.

- Improve the display design quality, by using, for example, an ergonomic guideline

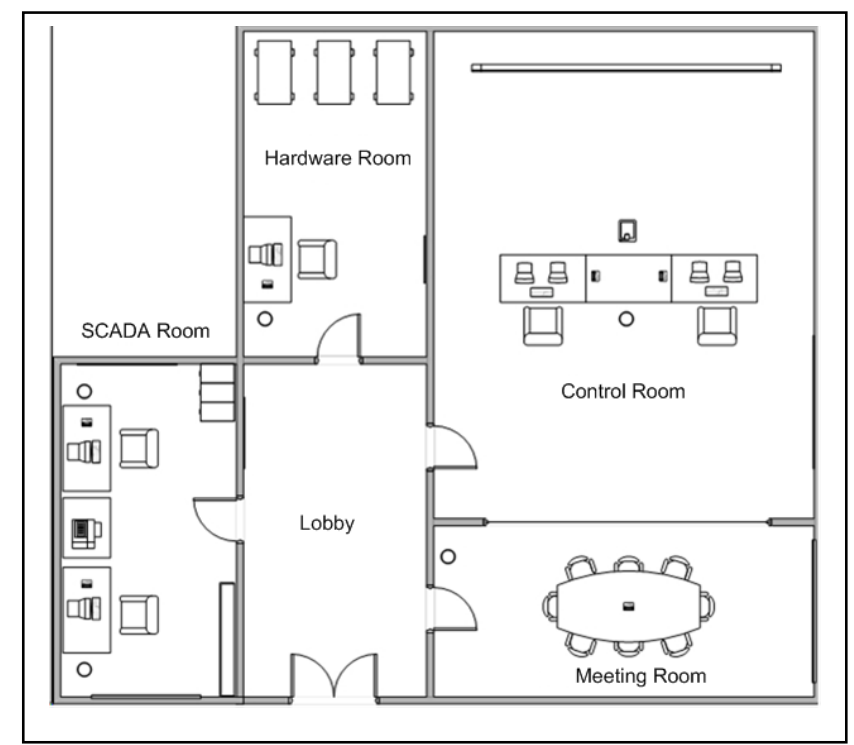

Figure 2. An engineering student (MsC Automatic Control and Robotics) in the role of control room designer: after a meeting and a questionnaire with the SAF staff, this is a possible SAF layout in order to differenciate all the tasks (supervisory control, maintenance, display design, usability testing)

\section{B. SAF display evaluation}

The experimental study is the evaluation of the SAF interface with the collaboration of control engineering students from Technical University of Catalonia. From Vilanova i la Geltrú city, twenty five students monitored the SAF interface for three weeks. The students assign a numeric value to each indicator of the GEDIS guideline [8] and propose interface improvement.

The GEDIS guide is a method that seeks to cover all the aspects of the interface design [9]. From the initial point of view of strategies for effective human-computer interaction applied to supervision tasks in industrial control room [10], [11].

The GEDIS guide offers design recommendations at the moment of creation of the interface as well as recommendations of improvement for already created interfaces.

The GEDIS guide is composed of two parts: description of ten indicators and measure of ten indicators. The indicators have been defined from extracted concepts of other generic human factors guidelines, and from aspects of human interface design in human computer interaction. As an example, included indicators are: architecture, navigation, alarm design, use of color and text, human operator inputs, etc.

TABLE II.

GEDIS GUIDE INDICATORS (PART I)

\begin{tabular}{|c|c|}
\hline $\begin{array}{l}\text { Indicator name and } \\
\text { Subindicator name }\end{array}$ & $\begin{array}{l}\text { Numeric/qualitative range } \\
\text { and SAF numeric value }\end{array}$ \\
\hline Architecture & 1,7 \\
\hline Map existence & {$[\mathrm{YES}, \mathrm{NO}][5,0]$} \\
\hline Number of levels le & {$[\mathrm{le}<4, \mathrm{le}>4][5,0]$} \\
\hline $\begin{array}{l}\text { Division: plant, area, } \\
\text { subarea, team }\end{array}$ & {$[\mathrm{a}, \mathrm{m} . \mathrm{na}][5,3,0]$} \\
\hline Distribution & 3 \\
\hline Model comparison & {$[\mathrm{a}, \mathrm{m} . \mathrm{na}][5,3,0]$} \\
\hline Flow process & $\begin{array}{c}\text { [clear, medium, no clear] } \\
{[5.3,0]}\end{array}$ \\
\hline Density & {$[\mathrm{a}, \mathrm{m} . \mathrm{na}][5,3,0] \quad 3$} \\
\hline Navigation & 3 \\
\hline $\begin{array}{l}\text { Relationship with } \\
\text { architecture }\end{array}$ & {$[\mathrm{a}, \mathrm{m} . \mathrm{na}][5,3,0]$} \\
\hline Navig. between screens & {$[\mathrm{a}, \mathrm{m} . \mathrm{na}][5,3,0]$} \\
\hline Color & 5 \\
\hline $\begin{array}{c}\text { Absence of non } \\
\text { appropriate combinations }\end{array}$ & {$[\mathrm{YES}, \mathrm{NO}][5,0]$} \\
\hline Color number $\mathrm{c}$ & {$[4<\mathrm{c}<7, \mathrm{c}>7][5,0] 5$} \\
\hline $\begin{array}{c}\text { Blink absence (no alarm } \\
\text { situation) }\end{array}$ & {$[\mathrm{YES}, \mathrm{NO}][5,0]$} \\
\hline $\begin{array}{c}\text { Contrast screen versus } \\
\text { graphical objects }\end{array}$ & {$[\mathrm{a}, \mathrm{m} . \mathrm{na}][5,3,0]$} \\
\hline Relationship with text & {$[\mathrm{a}, \mathrm{m} . \mathrm{na}][5,3,0] 5$} \\
\hline Text font & 3,2 \\
\hline Font number $\mathrm{f}$ & {$[\mathrm{f}<4, \mathrm{f}>4]$} \\
\hline $\begin{array}{c}\text { Absence of small font } \\
\text { (smaller 8) }\end{array}$ & {$[\mathrm{YES}, \mathrm{NO}][5,0] 0$} \\
\hline $\begin{array}{c}\text { Absence of non } \\
\text { appropriate combinations }\end{array}$ & {$[\mathrm{YES}, \mathrm{NO}][5,0] 5$} \\
\hline Abbreviation use & {$[\mathrm{a}, \mathrm{m} . \mathrm{na}][5,3,0] 3$} \\
\hline
\end{tabular}


TABLE III.

GEDIS GUIDE INDICATORS (PART II)

\begin{tabular}{|c|c|}
\hline $\begin{array}{l}\text { Indicator name and } \\
\text { Subindicator name }\end{array}$ & $\begin{array}{l}\text { Numeric/qualitative range } \\
\text { and SAF numeric value }\end{array}$ \\
\hline Status of the devices & 4 \\
\hline $\begin{array}{c}\text { Uniform icons and } \\
\text { symbols }\end{array}$ & {$[\mathrm{a}, \mathrm{m} . \mathrm{na}][5,3,0] \quad 3$} \\
\hline $\begin{array}{c}\text { Status team } \\
\text { representativeness }\end{array}$ & {$[\mathrm{YES}, \mathrm{NO}][5,0] 5$} \\
\hline Process values & 3 \\
\hline Visibility & {$[\mathrm{a}, \mathrm{m} . \mathrm{na}][5,3,0] 3$} \\
\hline Location & {$[\mathrm{a}, \mathrm{m} . \mathrm{na}][5,3,0] 3$} \\
\hline Graphs and tables & 4 \\
\hline Format & {$[\mathrm{a}, \mathrm{m} . \mathrm{na}][5,3,0] 3$} \\
\hline Visibility & {$[\mathrm{a}, \mathrm{m} . \mathrm{na}][5,3,0] 3$} \\
\hline Location & {$[\mathrm{a}, \mathrm{m} . \mathrm{na}][5,3,0] 5$} \\
\hline Grouping & {$[\mathrm{a}, \mathrm{m} . \mathrm{na}][5,3,0] 5$} \\
\hline Data-entry commands & 3 \\
\hline Visibility & {$[\mathrm{a}, \mathrm{m} . \mathrm{na}][5,3,0] 3$} \\
\hline Usability & {$[\mathrm{a}, \mathrm{m} . \mathrm{na}][5,3,0] 3$} \\
\hline Feedback & {$[\mathrm{a}, \mathrm{m} . \mathrm{na}][5,3,0] 3$} \\
\hline Alarms & 3,8 \\
\hline $\begin{array}{l}\text { Visibility of alarm } \\
\text { window }\end{array}$ & {$[\mathrm{a}, \mathrm{m} . \mathrm{na}][5,3,0] 3$} \\
\hline Location & {$[\mathrm{a}, \mathrm{m} . \mathrm{na}][5,3,0] 3$} \\
\hline Situation awareness & {$[\mathrm{YES}, \mathrm{NO}][5,0] 5$} \\
\hline Alarms grouping & {$[\mathrm{a}, \mathrm{m} . \mathrm{na}][5,3,0] 5$} \\
\hline $\begin{array}{l}\text { Information to the } \\
\text { operator }\end{array}$ & {$[\mathrm{a}, \mathrm{m} . \mathrm{na}][5,3,0] 3$} \\
\hline
\end{tabular}

Where $\mathrm{a}=$ appropriate, $\mathrm{m}=$ medium, na= no appropriate

The method to continue for the application of the GEDIS guide is: to analyze the indicator, to measure the indicator, obtain the global evaluation index and, finally, offer recommendations of improvement. The computation of the GEDIS guide global evaluation index is done according to the following formula:

Global_evaluation $=\frac{\sum_{i=1}^{10} p_{i} \text { ind }_{i}}{\sum_{i=1}^{10} p_{i}}$

In a first approach the mean value among the indicators expressed in (1) has been considered. That is to say, to each indicator an identical weight $\left(\mathrm{p}_{1}=\mathrm{p}_{2} \ldots=\mathrm{p}_{10}=1\right)$ has been assigned, although this will allow, in future studies, to weight the importance of some indicators with respect to others. The global evaluation is expressed in a scale that ranges from 0 to 5.

For the correct use of the GEDIS guide it is necessary the collaboration between the control room technical team and the human factors technician, since in some cases to analyze the indicator it is necessary to consider the expert's opinion.

The SAF interface global evaluation GEDIS index is 3.4. So it is necessary to indicate the SAF designer a set of important recommendations for further improvement:
- Revise the relationship between architecture, distribution and navigation indicators

- Improve the feedback between interface and human operator in data-entry commands indicator

- Improve the location of alarm indicator

With the GEDIS guide it is also possible to indicate the SAF designer a set of important recommendations about graphical screen improvements. For example, the Piscina ACS screen can be improved with a set of changes in color and text font indicators. Fig. 3 shows the original Piscina ACS screen and Fig. 4 shows revisited Piscina ACS screen.

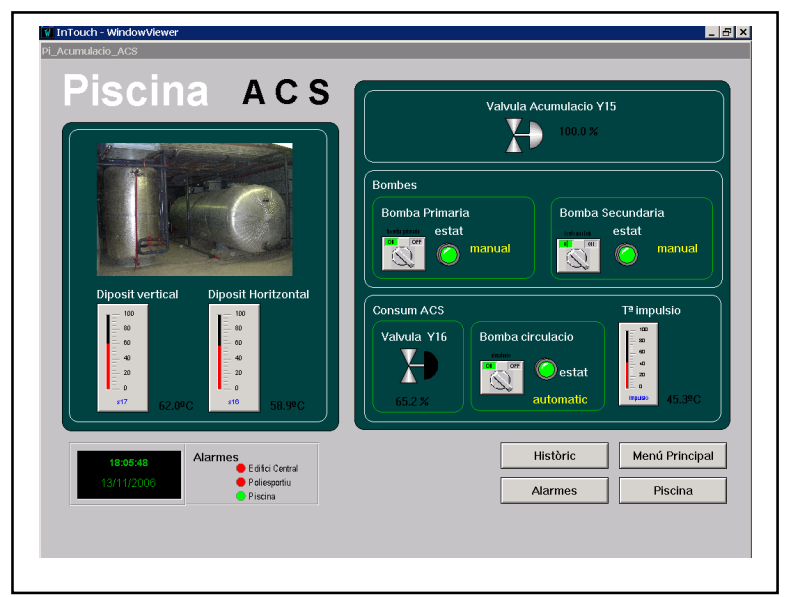

Figure 3. Original Piscina ACS screen (Catalan language)

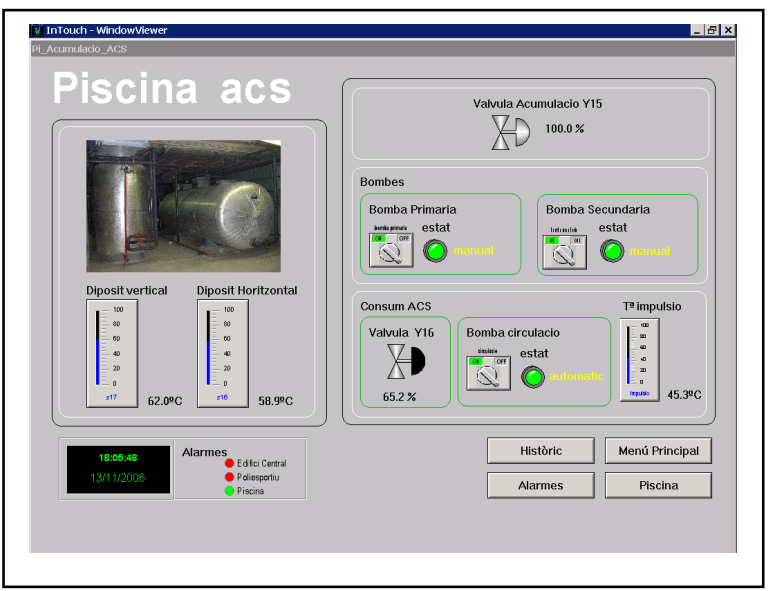

Figure 4. Piscina ACS revisited with changes in color indicator (Catalan language)

In order to evaluate the effectiveness of the venture from the educational perspective, at the end of course 2008-2009 the students from Integrated Production Systems subject (IPS subject from the technical school EPSEVG) answer an adaptation of the Student Evaluation of Educational Quality Questionnaire (SEEQ): 
- The students prefer dynamism in the class: more practical problems and less theoretical lessons.

- The students prefer to increase the number of laboratory sessions.

- The students think that the workload of the Msc Engineering in Automation and Industrial Electronics is high. Usually, these students work and don't have much time to do homework for their University Studies.

- The students are satisfied with the evaluation/assessment of the subject.

Fig. 5 shows one of the items related to the learning process.

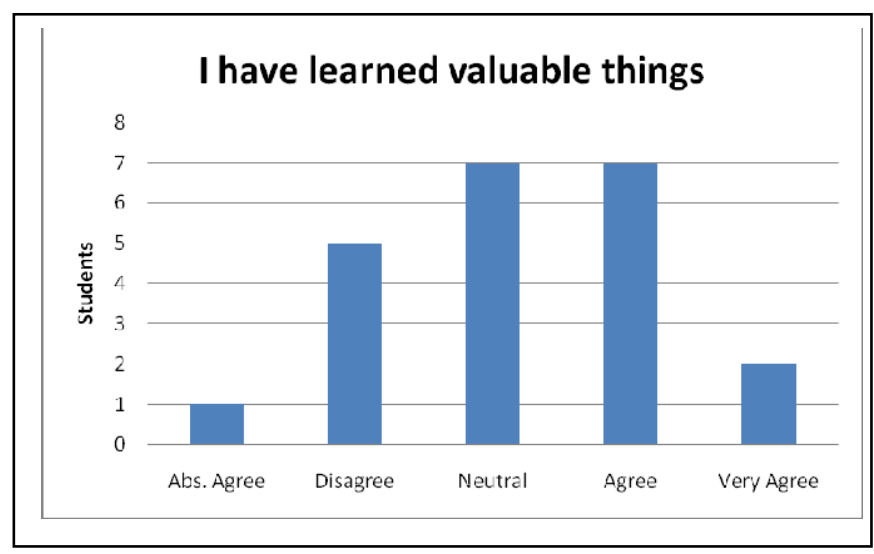

Figure 5. Inside the SEEQ "Learning" category (question two)

In order to evaluate the categories (Learning, Organization, Group Interaction, Examinations, and Assignments) the Table IV shows the comparison between some answers (only Good and Very Good answers) between the year 2006 and the year 2009. The questions are:

- Learning: A4 You have learned and understood the subject materials in this course

- Organization: C4 Practicum classes are useful and well prepared

- Group Interaction: D1 The own team and the other teams are a good tool to share ideas and knowledge

- Examinations: G2 Methods of evaluating student work are fair and appropriate

- Assignments: H3 Practicum tasks in the laboratory, contribute to appreciation and understanding of the subject

The Group Interaction assessment between the 2006 IPS Subject and the 2009 IPS Subject are similar. In the other categories, we can observe the increase in the 2009 subject students' assessment.

The next section shows a framework in order to introduce quality models concepts inside the engineering learning process.
TABLE IV. COMPARISON BETWEEN SOME ANSWERS

\begin{tabular}{|c|c|c|}
\hline SEEQ Category & $\begin{array}{c}\text { 2006 IPS } \\
\text { Subject }\end{array}$ & $\begin{array}{c}\text { 2009 IPS } \\
\text { Subject }\end{array}$ \\
\hline Learning & & \\
\hline A 4 & $75 \%$ & $80 \%$ \\
\hline Organization & & \\
\hline C4 & $55 \%$ & $80 \%$ \\
\hline Group Interaction & & \\
\hline D1 & $78.9 \%$ & $70 \%$ \\
\hline Examinations & & \\
\hline G2 & $26,3 \%$ & $60 \%$ \\
\hline Assignments & & \\
\hline H3 & $36,3 \%$ & $89 \%$ \\
\hline
\end{tabular}

\section{METRICS FOR EVALUATING HUMAN-AUtOMATION INTERACTION}

An example of methodological framework is the Process Model of the Usability Engineering and the Accessibility $\mathrm{MPIu}+\mathrm{a}$ developed by Toni Granollers [12] which gathers together all the cycle phases: requirements' analysis, design, implementation, launching, prototyping, evaluation and user, The analysis of requirements is a necessary previous research work in order to establish the best relationship among the human, the interface, and the task. For example, which is the user's profile? A human in the role of maintenance staff or supervisory control operator or display designer.

In the evaluation phase, and for the usability measure, it is necessary to have the contribution of the experimental studies carried out in the usability laboratories. The problem is how to define common metrics for human-automation interaction because each task and each automation system has singular properties (chemical control processes, flexible manufacturing systems, oil control processes, etc.) [13]. another problem is: which is the best interface, from the point of view of the user's experience? Some interfaces are appropriate for a few users but not for all users.

In human-computer studies it is necessary to define qualitative and quantitative performance rates. Following some ideas of the experts in usability studies and field studies, the tasks presented in the previous section demand a high level of activity planning that involve reasoning and decision making. It is possible to follow different approaches: the individual differences approach, the case study approach and the system characteristics approach. In this paper we follow the first approach. The studies of user's differences have diverse goals:

- To find ways of predicting performance

- To find and characterize individual variability. To find not only differences in the degree to which users are able to reach the goals, but also differences in how they perform, i.e. decision making strategies and user satisfaction 
From the point of view of usability engineering the proposed performance method can be summarized in three steps [14], [15]:

- Effectiveness measure

- Efficiency measure

- Users' satisfaction measure

Effectiveness is a measure of how well a human accomplishes the supervisory control task. For efficiency measures we find the ISO definition: "resources expended in relation to the accuracy and completeness with which users achieve goals" [16]. Effectiveness and efficiency measures are objective measures. For satisfaction measures we find user's questionnaire in order to achieve attitudes towards the use of the interface (how difficult is to learn the use of the interface, user's experience of discomfort in using the interface, etc.) [17].

Finally it is possible to define usability metrics. The number of attributes in usability engineering is three.

\section{Attributes $A=[$ Efficiency Effectiveness Satisfaction $]$}

In the case of objective measures, it's possible to add these attributes inside (2)

$$
\text { Usability }=\frac{\sum_{i=1}^{m} A_{i}}{m}
$$

The experimental session was carried out in the meeting room of the SAF enterprise at the Universitat Autónoma of Barcelona in December 2008, the two SAF staff members (maintenance head, computer science engineer) participated in an interview with a control engineering student playing the role of usability expert, they used the SAF display in a brief session in order to detect a possible device fault, and finally they answered a questionnaire about user interface satisfaction.

The questionnaire of the user interface satisfaction has been based on diverse classic references for this type of tools, for example the QUIS questionnaire [18]. The questionnaire has six questions related to the task where the user answers in concordance with the scale of Likert [19] with four answer options per question. Moreover, one more question has been added where the user assesses in a qualitative way the quality of the graphic display.

The six questions considered were:

- The task was difficult to understand

- The task has been long

- I have been confused, without having clear what it was necessary to do

- I needed to be very concentrated to carry out the task efficiently

- I have been pressured by the time

- I think that my performance has been correct
From the point of view of the maintenance head, the task is easy because he has great experience in process control and in fualt tolerant control. From the point of view of the computer science engineer the task is difficutl to understand for a novice user in process control and it's necessary to change some functionalities inside the screens in order to improve the quality of the supervisory control application (in example, the creation of an alarm system).

\section{CONCLUSIONS}

This paper has presented an experience that introduces a collaborative framework for undergraduate engineering project development. The idea presented here is based on representing the existing roles present in a professional framework with the additional value of integrating players from different universities and an industrial partner that provides services to the community. It is shown, among other points, how (i) the university itself can provide the customer points of view, (ii) promote collaborative work between different individual student projects within a global, large, project (iii) provide collaboration among different educational frameworks.

We will continue this work with usability testing in order to measure effectiveness, efficiency and satisfaction metrics over SAF supervisory operators. From the point of view of the authors, it's possible to apply the Cognitive Walkthrough method in order to obtain an analysis' task.

The SAF computer science engineer is assessing the use of the GEDIS guide in order to introduce changes and improve the quality of the graphical interface.

With the aid of well defined metrics and data collection it's possible to begin a statistical analysis as a future step of our work.

Finally, is necessary extend our approach in order to apply these methods to other subjects of the engineering curricula, study multiple roles, such as engineer-manager and find methods that help students to move from novice to expert.

\section{ACKNOWLEDGMENT}

Participation of the first and third authors is supported in part by an economical aid of the Technical University of Catalonia. Participation of the second author is supported in part by the Spanish CICYT program under contract DPI200763356. The authors thank Anton Gomà, head maintenance of the SAF system.

\section{REFERENCES}

[1] D. Zowghi and S. Paryani, "Teaching Requirements Engineering through Role Playing: Lessons Learnt ", 11th IEEE International Requirements Engineering Conference (RE'03), 2003

[2] W.-H. Wu, W.-F. Chen, T.-L. Wang and C.-H. Sue, "Developing and Evaluating a Game-Based Software Engineering Educational System". International Journal of Engineering Education, vol 24, N 4, pp. 681688, 2008.

[3] P. Mishra and M.J. Koehler, "Technological Pedagogical Content Knowledgement". Teachers College Record Volume 108, Number 6, pp. 1017-1054, June 2006 
[4] N.A. Kheir, H. J. Astrom, D. Auslander, K.C. Cheok, G.F. Franklin, M. Masten and M. Rabins. "Control systems engineering education". Automatica 32(2), 147-166, 1996.

[5] R. Vilanova, A. Gomà: A Collaborative Experience to show how the University can play the Industry role. 7th IFAC Symposium on Advances in Control Education. Madrid June 21-23, 2000

[6] P. Ponsa, B. Amante, J.A. Roman, S. Oliver, M. Díaz and J. Vives, "Higher education challenges: introduction of active methodologies in Engineering curricula". International Journal of Engineering Education, vol 25,(4), pp. 799-813, 2009.

[7] J. Noyes, M. Bransby, " People in control: human factors in control room design". IEE Control Engineering Series, 60. The Institute of Electrical Engineers, London, 2006.

[8] P. Ponsa, M. Díaz. "Creation of an ergonomic guideline for supervisory control interface design”. Springer LNCS Vol 4562, pp. 137.146, 2007

[9] P. Ponsa, B. Amante, M. Díaz. "Usability evaluation for the task of human supervisión in industrial control room". Revista Iberoamericana Automática, Informática Industrial RIAI Journal, Vol 6, (1), pp, 84-93, 2009

[10] I. Nimmo, “ Designing control rooms for humans”. Control Magazine, 2004.

[11] B. Shneiderman, “ Designing the user interface. Strategies for effective humna-computer interaction. Addison Wesley, 1997.
[12] T. Granollers, J. Lorés. " Incorporation of users in the evaluation of the usability by cognitive walktrhough". In HCI related papers of Interacción 2004. Springer, pp. 243-256, 2006

[13] A. Steinfeld, T. Fong, D. Kaber, M. Lewis, J. Scholtz, A. Schultz, M. Goodrich. "Common metrics for human-robot interaction". HRI'06, pp. 33-40, Sant Lake City, Utah, USA, 2006

[14] A. Sears and J.A. Jacko. “ The Human-computer interaction handbook”. Lawrence Erlbaum Associates, 2008

[15] J. Nielsen. Usability inspection methods. John Wiley \& Sons; 1994. ISBN: 0471018775

[16] ISO, 1998. "Ergonomic requirements for office work with visual displays terminals (VDTs)-Part 11: guidance on usability-Part 11: guidance on usability (ISO 9241-11: 1998)

[17] K. Hornbaek. " Current practice in measuring usability: challenges to usability studies and research". International Journal of HumanComputer Studies, 64, pp. 79-102, 2005

[18] J. P. Chin, V.A. Diehl and K.L. Norman. "Development of an instrument measuring user satisfaction of the human-computer interface.. Proceedings of SIGCHI '88, 1988, pp. 213-218

[19] Pedro Morales, Belén Urosa Sanz, Ángeles Blanco Blanco "Construcción de escalas de actitudes tipo Likert : una guía práctica" La Muralla ; Salamanca : Hespérides, cop. 2003 